\title{
POLÍTICA DE ACESSIBILIDADE E EXAME NACIONAL DO ENSINO MÉDIO (ENEM)*
}

\author{
Rogério Diniz JUNQUeIRA ${ }^{1}$ \\ Diléia Aparecida Martins ${ }^{2}$ \\ Cristina Broglia Feitosa Lacerda ${ }^{2}$
}

\begin{abstract}
RESUMO: Este trabalho analisa a política de acessibilidade ao Exame Nacional do Ensino Médio (Enem), no que concerne ao atendimento diferenciado oferecido aos participantes com deficiência e aos diferentes elementos e etapas de sua implementação, tais como: o edital, o portal, o sistema de inscrição, as provas adaptadas, os locais de prova, a formação e a atuação das equipes de aplicação, a aplicação da prova e a correção das redaçóes. Abordam-se dados das ediçóes de 2011 e 2012. A análise dos dados permite identificar a evolução quantitativa da participação das pessoas com deficiência no exame, mas, sobretudo, apontar lacunas e inconsistências do processo, levando-nos a concluir que a política de acessibilidade ao Enem não pode ficar restrita a alguns aspectos do atendimento diferenciado, mas deve envolver o processo completo.
\end{abstract}

Palavras-chave: Exame Nacional do Ensino Médio. Pessoas com deficiência. Acessibilidade. Atendimento diferenciado.

\section{THE ACCESSIBILITY POLICY AND THE NATIONAL EXAM OF UPPER SECONDARY EDUCATION (ENEM)}

ABSTRACT: This paper analyzes the accessibility policy of the National Exam of Upper Secondary Education (Enem), concerning the accommodations provided for participants with disabilities and many different elements and stages related to its implementation, such as the public notice, the website, the registration system, adapted tests, tests locations, the training and the work of application teams, the application of the test and the correction of essays. It were considered the 2011 and 2012 editions data, which analysis allows to identify the quantitative evolution of the participation of people with disabilities in the exam, but mainly recognize process gaps and inconsistencies, leading us to

\footnotetext{
*Esse estudo foi financiado pela Coordenação de Aperfeiçoamento de Pessoal de Nível Superior (CAPES). ${ }^{1}$ Instituto Nacional de Estudos e Pesquisas Educacionais Anísio Teixeira - Brasília (DF), Brasil.

E-mail: rogerio.junqueira@inep.gov.br

${ }^{2}$ Universidade Federal de São Carlos - São Carlos (SP), Brasil. E-mails: dileiamartins@gmail.com; cristinalacerda@uol.com.br

DOI: 10.1590/ES0101-733020171151513
} 
conclude that the policy accessibility to Enem cannot be restricted to some aspects regarding accommodations, but must involve the whole process.

Keywords: Exame Nacional do Ensino Médio. People with disabilities. Acessibility. Accommodations.

\section{LA POLITIQUE D'ACCESSIBILITÉ ET L'EXAMEN NATIONAL DE L'ENSEIGNEMENT SECONDAIRE (ENEM)}

RÉSUMÉ: Ce travail a pour but d'analyser la politique d'accessibilité à l'Examen National de l'Enseignement Secondaire (Enem) en ce qui concerne le traitement différencié dispensé aux participants ayant des handicaps, et aux différents éléments et étapes de sa mise en place: l'appel aux inscriptions, le portail web, le système d'inscription, les épreuves adaptées, les lieux d'application de l'évaluation, la formation et l'action des équipes d'application, l'application de l'examen et la correction des rédactions. Les données examinées ici, concernant les années 2011 et 2012, permettent d'identifier l'évolution quantitative de la participation des personnes handicapées dans cet examen, mais mettent davantage en avant des lacunes et des inconsistances de ce processus - ce qui nous mène à conclure que la politique d'accessibilité à l'Enem ne peut pas seulement se restreindre à certains aspects de ce traitement différencié, mais doit tout autant impliquer l'ensemble de son processus.

Mots-clés : Exame Nacional do Ensino Médio. Personnes handicapées. Accessibilité. Traitement différencié.

\section{Introdução}

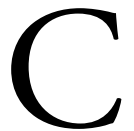

riado em 1998, com o objetivo de avaliar competências e habilidades desenvolvidas ao longo da educação básica por seus concluintes ou egressos, o Exame Nacional do Ensino Médio (Enem) teve seus resultados crescentemente utilizados por organizaçóes do mundo do trabalho; ao mesmo tempo, diversas Instituições de Ensino Superior (IESs) passaram a adotá-lo como instrumento de seleção.

No início dos anos 2000, o exame já contava com mais de 3 milhóes de participantes. Em 2004, passou a ser utilizado como critério de seleção para os estudantes que concorriam à bolsa no Programa Universidade para Todos (ProUni). Em 2009, sofreu profunda reformulação, e o Instituto Nacional de Estudos e Pesquisas Educacionais Anísio Teixeira (Inep), autarquia federal responsável pelo exame, passou a calcular as proficiências dos seus participantes com base na Teoria 
da Resposta ao Item (TRI) ${ }^{1}$. Nessa ocasião, o Ministério da Educação (MEC) decidiu tornar a prova a principal via de acesso às universidades federais.

Com efeito, em 2014, 115 IESs brasileiras e algumas estrangeiras já utilizavam os resultados do exame, complementando ou substituindo o vestibular. Em face de ser o Enem um relevante instrumento avaliativo e de ter se tornado um dos principais mecanismos de acesso ao ensino superior, contando com mais de 8,7 milhôes de inscritos em 2014, as questôes atinentes à acessibilidade de pessoas com deficiência ao certame passam a merecer maior atenção e a exigir providências e recursos para assegurá-la, garantindo, com isso, equidade e isonomia ao exame.

O Decreto n.o 3.298/1999 (BRASIL, 1999), ao regulamentar a Lei n. ${ }^{\circ} 7.853 / 1989$ (BRASIL, 1989), que dispóe sobre a Política Nacional para a Integração da Pessoa Portadora de Deficiência, reitera que cabe aos órgãos públicos e às entidades do poder público assegurar à pessoa com deficiência o pleno exercício de seus direitos básicos. A garantia de tais direitos está prevista na Lei n. ${ }^{\circ}$ 10.098/2000 (BRASIL, 2000), que estabelece normas gerais e critérios para a promoção da acessibilidade das pessoas portadoras de deficiência ou com mobilidade reduzida mediante a supressão de barreiras e obstáculos em vias e espaços públicos. Compreende-se por acessibilidade a possibilidade e a condição de alcance para utilização, com segurança e autonomia, dos espaços, mobiliários e equipamentos, das edificaçóes e dos sistemas e meios de comunicação para pessoas com deficiência, transtornos globais do desenvolvimento e altas habilidades/ superdotação ${ }^{2}$. Nesse sentido, acessibilidade é um atributo essencial do ambiente, visando garantir a qualidade de vida das pessoas. É fundamental que a acessibilidade esteja presente no meio físico e nos meios de comunicação e de informação, em qualquer lugar de uso público em todo território nacional. Trata-se de tema ainda pouco difundido e as políticas públicas precisam estar atentas à obrigatoriedade de implementaçáo da acessibilidade. Novas formas de pensar e agir na sociedade precisam ser fomentadas visando o bom uso dos recursos públicos para garantir a realização de direitos e cidadania.

A Lei n. ${ }^{\circ}$ 10.436/2002 (BRASIL, 2002) - que aborda os direitos linguísticos dos surdos, ao dispor sobre a Língua Brasileira de Sinais (Libras) - e o Decreto n. ${ }^{\circ}$ 5.626/2005 (BRASIL, 2005) - que a regulamenta - reforçam que a Libras, enquanto meio legítimo de comunicação e expressão, deve compor os espaços formativos de profissionais da educação e da saúde, como também reger a qualificação de profissionais bilíngues: tradutores e intérpretes de Libras (TILS), professores bilíngues, professores e instrutores de Libras devidamente capacitados para o exercício de suas funções. O Decreto dispóe, ainda, que as instituiçóes federais de ensino devem, obrigatoriamente, garantir às pessoas surdas condiçóes de acesso em seus processos seletivos. Por sua vez, o Decreto n. ${ }^{\circ}$ 5.296/2004 ${ }^{3}$ (BRASIL, 2004) define que o tratamento diferenciado às pessoas com deficiência 
deve contemplar adequações para a acessibilidade no campo da deficiência física, auditiva, visual e múltipla, da surdocegueira e da mobilidade reduzida.

À legislação, soma-se a Portaria do MEC n.o 807/2010 (BRASIL, 2010), que dispóe que a aplicação do Enem deve considerar questóes de acessibilidade e inclusão das pessoas com deficiência. Assim, o Inep - responsável por elaborar as Matrizes de Referência (INEP, 2013); formar as equipes elaboradoras de itens; definir as amostras para o pré-teste; realizar os cálculos psicométricos; definir as provas e as matrizes de correção; elaborar editais; produzir o sistema de inscrição eletrônica; contratar empresas aplicadoras; definir os municípios onde realizar as provas e os termos de aplicação; calcular proficiências e disseminar os resultados também é incumbido de adaptar as provas; produzir os instrumentos de apoio à atuação dos ledores; definir os critérios da correção diferenciada das redaçóes, bem como dos termos do atendimento diferenciado ${ }^{4}$.

Para a aplicação das provas, o Inep contrata empresas e, para garantir a distribuição e a segurança, faz convênios com os Correios, as Secretarias de Segurança Pública, a Polícia Federal, o Ministério da Defesa, entre outros. A escolha dos locais de prova, a contratação e a formação das equipes que atuam na aplicação e das que fazem a correção das redaçóes ficam sob a responsabilidade das empresas aplicadoras 5 .

\section{A inscrição e a participação de pessoas com deficiência no Enem}

Neste artigo, realizamos uma análise descritiva dos microdados ${ }^{6}$ mais recentemente divulgados pelo Inep: os das ediçóes de 2011 e 2012 do Enem (INEP, $2014 ; 2015)^{7}$. Trata-se de um biênio importante no campo do atendimento diferenciado no Enem, pois mudanças significativas foram introduzidas em 2012: melhorias no sistema de inscrição eletrônica (a dotação de maior navegabilidade para programas leitores de tela e a inclusão dos campos "autismo" e "surdocegueira"); o aprimoramento do atendimento (com a exigência de maior rigor nas capacitaçóes e na escolha dos locais de prova, etc.); a adoção de matrizes de correção específicas das provas escritas pelos participantes com surdez, deficiência auditiva e dislexia. Tais providências foram determinantes para o Inep implementar mudanças nas ediçóes seguintes. As alterações no sistema de inscrição mostram-se relevantes para a acessibilidade, a identificação de inconsistências e a maior confiabilidade dos dados, contribuindo para uma melhor compreensão de processos e resultados e a identificação de fragilidades.

$\mathrm{Na}$ edição de 2010, inscreveram-se 17.432 pessoas com deficiência e 9.867 pessoas com mobilidade reduzida (INEP, 2013). No biênio seguinte, conforme a Tabela 1, os inscritos com deficiência alcançaram, respectivamente, 21.873 e 25.107 , perfazendo um aumento de $25,5 \%$, entre 2010 e 2011 , e de 
14,8\%, entre 2011 e 2012. Assim, embora crescente, o conjunto das pessoas com deficiência configura um contingente extremamente reduzido: as pessoas com deficiência representaram cerca de $0,4 \%$ em relação tanto ao total de inscritos quanto ao de participantes ${ }^{8}$ do exame?

Um dos cuidados importantes a se tomar diante dos dados relativos à inscrição ou à participação no Enem é lembrar que o sistema de inscrição permite que, em caso de deficiência múltipla, a pessoa interessada informe cada uma de suas condições para, em seguida, solicitar os recursos e auxílios necessários no atendimento diferenciado, de modo que o número informado de deficiências não corresponde linearmente ao número de inscritos ou participantes com deficiência ou vice-versa.

Vale notar que os microdados relativos às quantidades de deficiências referem-se, diretamente, àquelas informadas no ato da inscrição e mais tarde confirmadas, sem, no entanto, considerar as que, em uma análise posterior, sejam passíveis de inferência ${ }^{10}$. Com efeito, pela análise dos microdados, observa-se que, em 2012, houve um expressivo aumento no contingente de pessoas com deficiência que solicitaram atendimento diferenciado sem informar sua condiçáo no ato da inscriçáo. Em 2011, esse contingente representou 5,0\% do total de pessoas com deficiência inscritas e 5,2\% das participantes. No ano seguinte, essas cifras passaram a 49,8 e $50,3 \%$, respectivamente. Esse aumento de 1.099 para 12.510 (um incremento de $1.038,3 \%)$ no número de inscritos com deficiência que, sem informá-la, solicitaram atendimento diferenciado representou um desafio logístico e levou o Inep a providenciar mudanças no sistema de inscriçãa ${ }^{11}$.

A Tabela 2 traz dados relativos à quantidade de deficiências informadas no ato da inscrição do Enem em 2011 e 2012. Os contingentes de pessoas que informaram deficiência física foram os maiores: em 2011, foram 8.745 inscritos $(39,2 \%)$ e 5.764 participantes (36,8\%); em 2012, esses números foram de 4.982 $(36,8 \%)$ e $3.169(34 \%)$, respectivamente. Em ambas as ediçóes, a baixa visão constituiu o segundo contingente entre participantes e inscritos: em 2011, 6.143

Tabela 1

Inscritos e participantes com e sem deficiência no Enem em 2011 e 2012, Brasil.

\begin{tabular}{l|c|c|c|c|c|c|c|c}
\hline \multirow{2}{*}{ Condiçáo } & \multicolumn{4}{|c|}{$\mathbf{2 0 1 1}$} & \multicolumn{4}{c}{$\mathbf{2 0 1 2}$} \\
\cline { 2 - 9 } & $\mathbf{I n s c r i t o s}$ & \multicolumn{2}{c|}{ Participantes } & \multicolumn{2}{c}{ Inscritos } & \multicolumn{2}{c}{ Participantes } \\
\cline { 2 - 9 } & $\mathbf{n}$ & $\mathbf{\%}$ & $\mathbf{n}$ & $\mathbf{\%}$ & $\mathbf{n}$ & $\mathbf{\%}$ & $\mathbf{n}$ & $\mathbf{\%}$ \\
\hline $\begin{array}{l}\text { Pessoas sem } \\
\text { deficiência }\end{array}$ & 5.358 .983 & 99,59 & 3.848 .422 & 99,61 & 5.765 .958 & 99,57 & 4.062 .437 & 99,57 \\
\hline $\begin{array}{l}\text { Pessoas com } \\
\text { deficiência* }\end{array}$ & 21.873 & 0,41 & 15.231 & 0,39 & 25.107 & 0,43 & 17.449 & 0,43 \\
\hline Total & 5.380 .856 & 100 & 3.863 .653 & 100 & 5.791 .065 & 100 & 4.079 .886 & 100 \\
\hline
\end{tabular}

Fonte: INEP (2014; 2015).

*Incluidos casos de transtornos globais do desenvolvimento e transtornos funcionais específicos. 
$(27,5 \%)$ inscritos e 4.277 (27,3\%) participantes. No ano seguinte, $3.327(24,6 \%)$ informaram baixa visão na inscrição e 2.205 (23,7\%) foram esses participantes.

Por outro lado, mesmo se somadas, surdez e deficiência auditiva comparecem apenas em $3^{\circ}$ lugar em ambas as ediçóes: em 2011, 3.771 inscritos (16,9\%) e 2.945 participantes (18,9\%), e, em 2012, 1.868 inscritos (13,8\%) e 1.316 participantes $(14,1 \%)$. Essa participação relativamente menor de pessoas com surdez ou deficiência auditiva deve merecer atenção do poder público em geral e do Inep em particular, pois sinaliza uma difusa falta de incentivo à participação no Enem e uma possível percepção de insuficiente acessibilidade na divulgação do exame, no edital, no sistema de inscrição e, principalmente, em relação à prova e à sua aplicação, negando condiçóes de acessibilidade preconizadas pela legislação vigente.

Depois das pessoas com surdocegueira, os portadores de deficiência intelectual constituem, desde 2010, o contingente com menor presença entre os inscritos e os participantes no Enem. Em 2011, inscreveram-se ao exame 529 pessoas com deficiência intelectual e 421 delas participaram efetivamente, representando 2,37\% dos inscritos e 2,69\% dos participantes com deficiência. No ano seguinte, elas foram 378 (2,79\%) e 257 (2,76\%), respectivamente. Ao mesmo

\section{Tabela 2}

Deficiências informadas no ato da inscrição do Enem em 2011 e 2012, Brasil.

\begin{tabular}{|c|c|c|c|c|c|c|c|c|}
\hline \multirow{3}{*}{ Tipos* } & \multicolumn{4}{|c|}{2011} & \multicolumn{4}{|c|}{2012} \\
\hline & \multicolumn{2}{|c|}{ Inscritos } & \multicolumn{2}{|c|}{ Participantes } & \multicolumn{2}{|c|}{ Inscritos } & \multicolumn{2}{|c|}{ Participantes } \\
\hline & $\mathbf{n}$ & $\%$ & $\mathbf{n}$ & $\%$ & $\mathbf{n}$ & $\%$ & $\mathbf{n}$ & $\%$ \\
\hline Baixa visão & 6.143 & 27,52 & 4.277 & 27,33 & 3.327 & 24,56 & 2.205 & 23,67 \\
\hline Cegueira & 941 & 4,22 & 687 & 4,39 & 853 & 6,30 & 632 & 6,78 \\
\hline Surdez & 1.340 & 6,00 & 1.046 & 6,68 & 699 & 5,16 & 493 & 5,29 \\
\hline $\begin{array}{l}\text { Deficiência } \\
\text { auditiva }\end{array}$ & 2.431 & 10,89 & 1.909 & 12,20 & 1.169 & 8,63 & 823 & 8,83 \\
\hline Surdocegueira** & - & - & - & - & 1 & 0,01 & 0 & 0 \\
\hline $\begin{array}{l}\text { Deficiência } \\
\text { física }\end{array}$ & 8.745 & 39,18 & 5.764 & 36,84 & 4.982 & 36,78 & 3.169 & 34,01 \\
\hline $\begin{array}{l}\text { Deficiência } \\
\text { intelectual }\end{array}$ & 529 & 2,37 & 421 & 2,69 & 378 & 2,79 & 257 & 2,76 \\
\hline Autismo $^{(2)}$ & - & - & - & - & 57 & 0,42 & 44 & 0,47 \\
\hline Dislexia & 1.265 & 5,67 & 782 & 5,00 & 882 & 6,51 & 732 & 7,86 \\
\hline $\begin{array}{l}\text { Déficit de } \\
\text { atenção }\end{array}$ & 927 & 4,15 & 761 & 4,86 & 1.198 & 8,84 & 962 & 10,33 \\
\hline Total & 22.321 & 100 & 15.647 & 100 & 13.546 & 100 & 9.317 & 100 \\
\hline
\end{tabular}

Fonte: INEP (2014; 2015).

*Incluidos casos de deficiência, transtornos globais

do desenvolvimento e transtornos funcionais específicos, com possiveis múltiplas marcaçóes.

**Campo introduzido em 2012. 
tempo, chama a atenção o aumento de $29,2 \%$ no número de inscritos que informaram déficit de atenção. Eles passaram de 927, em 2011, para 1.198, em 2012, em um ano em que houve aumento no número de inscritos que deixaram de informar a deficiência.

As Tabelas 3 e 4 permitem identificar as quantidades de deficiências informadas no ato da inscrição em 2011 e 2012. Elas deixam claro que, mesmo no caso de deficiências ou transtornos com reduzido número de inscritos - como foi o caso da surdocegueira, em 2012, com apenas uma pessoa - não há deficiência que permaneça sempre isolada, sem a ocorrência ou a associação com outras deficiências e outros transtornos globais do desenvolvimento ou transtornos funcionais específicos. Ainda que de maneira variada, as deficiências múltiplas apresentam presença constante, e algumas delas são relativamente expressivas.

Em 2011, entre os 8.745 inscritos que declararam deficiência física e os 6.143 que informaram baixa visão, 130 declararam ambas as condiçóes. No ano seguinte, os inscritos com deficiência física foram 4.982, e os com baixa visão, 3.327; no entanto, 144 inscritos informaram deficiência múltipla em que se associavam essas duas naturezas. Ou seja, embora tenha havido uma queda de $43 \%$ no número de inscritos com deficiência física e de $45,8 \%$ entre os que informaram baixa visão, houve um incremento de $10,8 \%$ entre os que declararam ambas. Os dados referentes ao ano de 2012 poderão ser observados na Tabela 4.

Os aumentos mais expressivos foram verificados nos casos em que deficiência intelectual e déficit de atenção se associaram a outras deficiências ou transtornos. Assim, embora geralmente tenha havido, no ato da inscriçáo, uma redução do número de declarações de deficiência entre essas duas edições do Enem,

\section{Tabela 3}

Quantidade de deficiências informadas pelos inscritos no Enem em 2011, Brasil.

\begin{tabular}{|c|c|c|c|c|c|c|c|c|c|}
\hline 2011 & $\begin{array}{l}\text { Baixa } \\
\text { visão }\end{array}$ & Cegueira & Surdez & $\begin{array}{c}\text { Defic. } \\
\text { auditiva }\end{array}$ & $\begin{array}{l}\text { Defic. } \\
\text { física }\end{array}$ & $\begin{array}{c}\text { Defic. } \\
\text { Intelectual }\end{array}$ & Dislexia & $\begin{array}{c}\text { Déficit } \\
\text { de } \\
\text { atençáo }\end{array}$ & Total \\
\hline Baixa visão & 5.828 & 42 & 15 & 47 & 130 & 18 & 17 & 46 & 6.143 \\
\hline Cegueira & 42 & 881 & 3 & 1 & 4 & 2 & 3 & 5 & 941 \\
\hline Surdez & 15 & 3 & 325 & 983 & 6 & 3 & 1 & 4 & 1.340 \\
\hline $\begin{array}{l}\text { Deficiência } \\
\text { auditiva }\end{array}$ & 47 & 1 & 983 & 1.320 & 39 & 12 & 13 & 16 & 2.431 \\
\hline $\begin{array}{l}\text { Deficiência } \\
\text { física }\end{array}$ & 130 & 4 & 6 & 39 & 8.491 & 20 & 17 & 38 & 8.745 \\
\hline $\begin{array}{l}\text { Deficiência } \\
\text { intelectual }\end{array}$ & 18 & 2 & 3 & 12 & 20 & 424 & 17 & 33 & 529 \\
\hline Dislexia & 17 & 3 & 1 & 13 & 17 & 17 & 1.079 & 118 & 1.265 \\
\hline $\begin{array}{l}\text { Déficit de } \\
\text { atençáo }\end{array}$ & 46 & 5 & 4 & 16 & 38 & 33 & 118 & 667 & 927 \\
\hline
\end{tabular}

Fonte: INEP (2014; 2015). 
houve um incremento na informação quanto à ocorrência conjunta de déficit de atenção com diversas deficiências. Por exemplo, o número de inscritos que informaram associação de déficit de atenção e baixa visão passou de 46 para 73 (um aumento de 58,7\%); déficit de atenção e deficiência intelectual, de 33 para 76 (130,3\%); déficit de atençâo e dislexia, de 118 para 234 (98,3\%).

Mesmo com a redução de 529 para 378 no número de inscritos que informaram deficiência intelectual (uma queda de 28,5\%), também houve um forte aumento nas informaçóes que associaram essa deficiência a outras deficiências ou transtornos. Por exemplo, a sua ocorrência com a baixa visão foi de 18 para 41; com a deficiência física, de 20 para 35; com a dislexia, de 17 para 22; com o déficit

\section{Tabela 4}

Quantidade de deficiências informadas pelos inscritos no Enem em 2012, Brasil.

\begin{tabular}{|c|c|c|c|c|c|c|}
\hline 2012 & $\begin{array}{c}\text { Baixa } \\
\text { visáo }\end{array}$ & Cegueira & Surdez & \multicolumn{2}{|c|}{$\begin{array}{c}\text { Defic. } \\
\text { auditiva }\end{array}$} & $\begin{array}{l}\text { Surdo- } \\
\text { cegueira }\end{array}$ \\
\hline Baixa visão & 2.957 & 37 & 10 & \multicolumn{2}{|l|}{42} & 1 \\
\hline Cegueira & 37 & 798 & 2 & \multicolumn{2}{|l|}{3} & 1 \\
\hline Surdez & 10 & 2 & 539 & \multicolumn{2}{|l|}{126} & 1 \\
\hline Deficiência auditiva & 42 & 3 & 126 & \multicolumn{2}{|l|}{915} & 1 \\
\hline Surdocegueira* & 1 & 1 & 1 & \multicolumn{2}{|l|}{1} & 1 \\
\hline Deficiência física & 144 & 6 & 10 & \multicolumn{2}{|l|}{44} & 1 \\
\hline Deficiência intelectual & 41 & 2 & 4 & \multicolumn{2}{|l|}{16} & 1 \\
\hline Autismo & 1 & 0 & 2 & \multicolumn{2}{|l|}{2} & 0 \\
\hline Dislexia & 21 & 0 & 1 & \multicolumn{2}{|l|}{6} & 0 \\
\hline Déficit de atenção & 73 & 4 & 4 & \multicolumn{2}{|l|}{14} & 0 \\
\hline 2012 & $\begin{array}{l}\text { Defic. } \\
\text { física }\end{array}$ & $\begin{array}{c}\text { Defic. } \\
\text { intelect. }\end{array}$ & Autismo & Dislexia & $\begin{array}{l}\text { Déf. de } \\
\text { atençáo }\end{array}$ & Total \\
\hline Baixa visão & 144 & 41 & 1 & 21 & 73 & 3.327 \\
\hline Cegueira & 6 & 2 & 0 & 0 & 4 & 853 \\
\hline Surdez & 10 & 4 & 2 & 1 & 4 & 699 \\
\hline Deficiência auditiva & 44 & 16 & 2 & 6 & 14 & 1.169 \\
\hline Surdocegueira* $^{*}$ & 1 & 1 & 0 & 0 & 0 & $1^{(2)}$ \\
\hline Deficiência física & 4.682 & 35 & 1 & 12 & 47 & 4.982 \\
\hline Deficiência intelectual & 35 & 176 & 5 & 22 & 76 & 378 \\
\hline Autismo & 1 & 5 & 36 & 2 & 8 & 57 \\
\hline Dislexia & 12 & 22 & 2 & 584 & 234 & 882 \\
\hline Déficit de atenção & 47 & 76 & 8 & 234 & 738 & 1.198 \\
\hline
\end{tabular}

*Houve inscrição de uma pessoa com surdocegueira, a qual fez múltiplas marcaçōes. 
de atenção, de 33 para 76. Esses aumentos no registro das informaçóes em que se associaram a deficiência intelectual ou o déficit de atenção a outras deficiências e transtornos devem merecer ulteriores estudos para verificar se constituem uma tendência, entender o que os produz e, assim, buscar uma compreensão dos processos de identificação ou atribuição da deficiência intelectual e do transtorno de déficit de atenção, especialmente no contexto escolar.

Cabe observar que, nas ediçóes aqui analisadas, houve casos em que os inscritos informaram simultaneamente surdez e deficiência auditiva, ou cegueira e baixa visão. $\mathrm{E}$, mesmo após os contatos realizados com vistas a confirmar ou corrigir as informaçóes inconsistentes, pessoas continuavam a figurar simultaneamente como cegas e com baixa visão; outras, como surdas e com deficiência auditiva. Assim, em 2012, dos 2.814 participantes que informaram cegueira, baixa visão ou ambas as condiçóes, 609 informaram apenas cegueira, 2.182, exclusivamente baixa visão, e 23, as duas; dos 1.232 que informaram surdez e/ou deficiência auditiva, 409 declararam somente surdez, 739, unicamente deficiência auditiva, e 84, ambas ${ }^{12}$.

Essa dupla marcaçáo pode ser resultado de um conjunto de fatores, tais como: distintos entendimentos em torno das categorias relativas a deficiências empregadas no edital do exame; existência de diferentes maneiras de os sujeitos se autoidentificarem enquanto pessoas com deficiência, diante de uma variedade de contextos e significados; dúvidas, ansiedades, incompreensóes ou erros de marcação; insuficiência de acessibilidade do sistema de inscrição, entre outros. Nota-se, de todo modo, um movimento pela ampliaçáo de acesso aos direitos e à cidadania da pessoa com deficiência. Contudo, ao mesmo tempo, é preciso enfatizar que ainda é necessário percorrer um longo percurso, no qual devem ser tomadas medidas voltadas a prover melhores informaçôes, formação mais adequada, recursos apropriados, entre outros, para se garantir a devida e indispensável acessibilidade.

\section{A solicitação de auxílios e recursos de acessibilidade}

Nas ediçóes de 2011 e 2012, tal como ocorreu em 2010, os recursos de acessibilidade mais solicitados na inscrição foram "sala de fácil acesso" e "prova ampliada". Conforme mostra a Tabela 5, em 2011, foram 9.285 solicitações (34,77\%) de "sala de fácil acesso" e, no ano seguinte, 15.588 (41,45\%). Para entender essas cifras relativamente elevadas, é preciso lembrar que, embora "sala de fácil acesso" seja um recurso usualmente solicitado por pessoas com deficiência física, ele pode ser disponibilizado para quase todas as deficiências (exceto surdez e deficiência auditiva), bem como para idosos e gestantes. A "prova ampliada" recebeu 5.940 (22,24\%) solicitaçóes em 2011 e 6.102 (16,22\%) em 2012.

Verifica-se que os serviços especializados mais solicitados foram "auxílio para transcriçáo", com 5.923 (22,18\%) pedidos em 2011 e 3.818 (10,15\%) em 
2012, seguido de "auxílio para leitura", com 2.444 (9,15\%) solicitaçóes no primeiro ano e $2.913(7,75 \%)$ no segundo.

Pelos microdados do Enem, observa-se o aumento do número de participantes que, mesmo sem informar deficiência, solicitaram "prova ampliada" (de 31, em 2011, para 2.264, em 2012), TILS (de 15 para 536), leitura labial (de 8 para 424) e intérprete e leitura labial (de 1 para 142). Nota-se também que, entre os participantes que informaram cegueira no ato da inscrição, 18 em 2011 e 8 em 2012 não solicitaram nenhum recurso ou auxílio para poder realizar as provas.

\section{Tabela 5}

Recursos e auxílios solicitados na inscrição do Enem em 2011 e 2012, Brasil.

\begin{tabular}{|c|c|c|c|c|c|c|c|c|}
\hline \multirow{3}{*}{$\begin{array}{l}\text { Recursos e } \\
\text { auxílios* }\end{array}$} & \multicolumn{4}{|c|}{$2011^{* *}$} & \multicolumn{4}{|c|}{$2012^{* *}$} \\
\hline & \multicolumn{2}{|c|}{ Inscritos } & \multicolumn{2}{|c|}{ Participantes } & \multicolumn{2}{|c|}{ Inscritos } & \multicolumn{2}{|c|}{ Participantes } \\
\hline & $\mathbf{n}$ & $\%$ & $\mathbf{n}$ & $\%$ & $\mathbf{n}$ & $\%$ & $\mathbf{n}$ & $\%$ \\
\hline $\begin{array}{l}\text { Prova em } \\
\text { Braille }\end{array}$ & 309 & 1,16 & 245 & 1,30 & 343 & 0,91 & 264 & 1,04 \\
\hline $\begin{array}{l}\text { Prova } \\
\text { ampliada }\end{array}$ & 5.940 & 22,24 & 4.140 & 21,99 & 6.102 & 16,22 & 4.178 & 16,43 \\
\hline $\begin{array}{l}\text { Intérprete de } \\
\text { Libras (ILS) }\end{array}$ & 1.590 & 5,95 & 1.247 & 6,62 & 1.779 & 4,73 & 1.326 & 5,21 \\
\hline Leitura labial & 1.215 & 4,55 & 942 & 5,00 & 1.509 & 4,01 & 1.143 & 4,49 \\
\hline $\begin{array}{l}\text { Guia- } \\
\text { intérprete*** }\end{array}$ & - & - & - & - & 2 & 0,01 & 0 & 0 \\
\hline $\begin{array}{l}\text { Auxílio para } \\
\text { leitura }\end{array}$ & 2.444 & 9,15 & 1.832 & 9,73 & 2.913 & 7,75 & 2.220 & 8,73 \\
\hline $\begin{array}{l}\text { Auxílio para } \\
\text { transcrição }\end{array}$ & 5.923 & 22,18 & 4.264 & 22,65 & 3.818 & 10,15 & 2.795 & 10,99 \\
\hline $\begin{array}{l}\text { Sala de fácil } \\
\text { acesso }\end{array}$ & 9.285 & 34,77 & 6.157 & 32,70 & 15.588 & 41,45 & 10.121 & 39,80 \\
\hline $\begin{array}{l}\text { Mesa para } \\
\text { cadeira de } \\
\text { rodas }^{* * *}\end{array}$ & - & - & - & - & 1.814 & 4,82 & 1.187 & 4,67 \\
\hline $\begin{array}{l}\text { Mesa e cadeira } \\
\text { separadas*** }\end{array}$ & - & - & - & - & 1.986 & 5,28 & 1.203 & 4,73 \\
\hline $\begin{array}{l}\text { Apoio de } \\
\text { perna*** }\end{array}$ & - & - & - & - & 1.748 & 4,65 & 987 & 3,88 \\
\hline $\begin{array}{l}\text { Classe em } \\
\text { unidade } \\
\text { hospitalar }\end{array}$ & - & - & - & - & 7 & 0,02 & 6 & 0,02 \\
\hline Total & 26.706 & 100 & 18.827 & 100 & 37.609 & 100 & 25.430 & 100 \\
\hline
\end{tabular}

Fonte: INEP (2014; 2015).

*Com possiveis múltiplas marcaçôes.

**Estão incluidas as solicitações de pessoas que não informaram a deficiência ou mobilidade reduzida. ***Opçóes de marcação introduzidas em 2012. 
A informaçáo incompleta ou inconsistente no momento da inscrição ou da confirmação das solicitações pode gerar dificuldades logísticas que, por sua vez, podem afetar o rendimento do participante. Medidas voltadas para a garantia de maior acessibilidade em cada etapa de elaboração e implementação do Enem contribuem também para amenizar esses problemas.

\section{As taxas de abstenção}

Considerado globalmente, o contingente das pessoas que informaram deficiência no ato da inscrição apresentou taxas de abstençáo um pouco superiores às verificadas entre os participantes sem deficiência. Essas taxas entre as pessoas sem deficiência foram de 28,2\% em 2011 e 29,5\% em 2012. Entre aquelas com deficiência foram, respectivamente, de 30,4 e 30,5\% (Tabela 1). Embora as taxas possam apresentar fortes variações de um ano para o outro, verifica-se que, nessas duas edições do Enem, a abstenção entre pessoas que informaram possuir cegueira, surdez, deficiência auditiva ou déficit de atenção foi, em alguns casos, praticamente igual, mas, na maioria deles, inferior à verificada entre o contingente que não informou deficiência (Tabela 2). Em 2012, ausentaram-se apenas 17,0\% das pessoas com dislexia, as quais, no ano anterior, tinham apresentado a mais alta da taxa de abstenção: $38,2 \%$.

Assim, as taxas de abstenção, embora apresentem alguma variação, tendem a ser maiores entre os contingentes com mais expressiva redução de mobilidade. Essa tendência fica evidenciada na Tabela 5: em 2012, os quatro recursos de acessibilidade cujos solicitantes apresentaram maiores taxas de abstenção foram aqueles geralmente disponibilizados para tal público (sala de fácil acesso) ou oferecidos prioritariamente para ele (mesa para cadeira de rodas, mesa com cadeira separada e apoio para perna).

A reduzida presença de pessoas com deficiência no Enem, em torno de $0,4 \%$ do total dos inscritos e dos participantes, e as taxas de abstenção observadas entre pessoas com diferentes tipos de deficiência indicam, entre outras coisas, a necessidade de se pensar, cada vez mais, a acessibilidade no terreno das açóes integradas, intersetoriais, com especial atenção para a necessidade de garantir e aprimorar açóes de acessibilidade nos diferentes espaços sociais.

\section{Algumas considerações sobre os auxílios e recursos de acessibilidade}

A primeira barreira ao Enem diz respeito à insuficiente acessibilidade ao portal do Inep, onde se encontram o edital e o sistema de inscrição. Para Kulpa (2009), as interfaces computacionais permitem que as pessoas se comuniquem com sistemas e naveguem em ambientes virtuais (web). Todavia, com a ampliação 
da tecnologia computacional, muitos sistemas tornaram-se complexos e a interpretação das mensagens pelo usuário nem sempre é possível. A acessibilidade deve abranger, além das codificaçóes para funcionar em leitores de tela, a comunicabilidade (apresentar linguagem compreendida por todo público a que se destina) e a usabilidade (permitir que o usuário encontre com facilidade as informaçóes procuradas). A comunicabilidade e a usabilidade podem se configurar como excludentes, pois estudantes com menos oportunidades tecnológicas podem ter dificuldades no acesso às informaçóes no portal do Inep.

Ao longo do processo - inscrição, confirmação da inscrição, informaçóes sobre local de prova, resultados, recursos, etc. -, todas as informaçóes relacionadas à prova precisariam estar plenamente disponíveis a todos os participantes. Tanto para a pessoa cega quanto para a pessoa surda, seria amplamente desejável um acesso que favorecesse a leitura e disponibilizasse janelas com conteúdo em Libras. Por se tratar de um portal e de um sistema de inscrição que o usuário precisa acessar inúmeras vezes, eles não podem constituir-se em uma barreira. Além disso, no ato da inscrição, há a solicitação de preenchimento de um questionário socioeconômico, que também é ofertado com acessibilidade limitada, o que prejudica a qualidade das informaçóes fornecidas, dificultando análises mais fidedignas acerca das condiçóes socioeconômicas e a checagem das necessidades do participante ${ }^{13}$. As alteraçóes no portal são importantes para prevenir inconsistências e garantir acessibilidade, maior confiabilidade dos dados e melhor atendimento. São necessários investimentos para um portal acessível, que atenda às exigências descritas nas normas técnicas estipuladas pelo governo federal (BRASIL, 2013).

Em relação ao acesso de pessoas cegas ao Enem, as principais medidas adotadas pelo Inep são: a adaptação dos itens da prova convencional que contêm recursos visuais; a transcrição da prova para a grafia Braille e a oferta de ledores/ transcritores, que devem atuar em dupla, em sala com apenas um participante. Esses especialistas não devem ser confundidos com os fiscais de sala; de acordo com os contratos com as empresas aplicadoras, precisam receber formação específica e, durante a prova, devem apoiar-se em um instrumento chamado Prova do Ledor, que, além das orientaçóes para os ledores, traz, em tinta, o mesmo conteúdo da prova transcrita em Braille.

O Ministério da Educação (BRASIL, 2006) recomenda que textos transcritos em grafia Braille apresentem gráficos e imagens também acessíveis pela via tátil, por entender ser fundamental assegurar à pessoa cega a possibilidade de consultar a imagem gráfica. No entanto, no Enem, as provas em Braille não trazem a transcrição dos recursos visuais presentes nas provas convencionais. Esses são substituídos por descrições, não raro, muito longas e complexas. Assim, itens produzidos seguindo raciocínio apoiado em imagens podem ser menos acessíveis aos participantes cegos, já que nem sempre a explicação do gráfico ou da figura é suficiente para oferecer a mesma condição de interpretação ofertada aos demais. 
Esse quadro é agravado pelo fato de que a Prova do Ledor também não traz as imagens, que na prova em Braille são apenas descritas. Assim, tanto o participante cego quanto os ledores que o auxiliam ficam impossibilitados de entender de maneira tátil (o primeiro) e visual (os segundos) as especificidades das curvas dos gráficos, as proporçóes entre diferentes figuras nos esquemas e assim por diante. Soma-se a isso o fato de apenas os itens com imagens na prova convencional passarem por adaptação, embora não se possa excluir que itens sem imagens possam apresentar eventuais barreiras. Essa forma de apresentação da prova em Braille e da Prova do Ledor pode produzir discrepâncias entre os parâmetros previamente calculados de um item durante o pré-teste, a proficiência do participante cego e as suas possibilidades de acertos e erros com base na TRI. Nos casos em que isso ocorrer, as médias obtidas por ele podem se mostrar ainda mais baixas, prejudicando-o ulteriormente. Soma-se a isso o fato de os participantes cegos terem de ditar suas redaçóes para os transcritores, uma vez que elas não podem ser entregues em Braille. Isso, além de tomar mais tempo e comportar maior desgaste físico e emocional, pode ensejar situaçôes em que mal-entendidos entre os envolvidos levem a uma eventual produção de erros de ortografia, pontuação, entre outras consequências, pelo transcritor, e não pelo participante.

Uma vez que os itens são elaborados a partir de Matrizes de Referências que não consideram as especificidades das pessoas cegas, eles tendem a se apoiar em uma compreensão visual de mundo, o que pode acrescentar dificuldades para os participantes cegos. Atualmente, depois de confeccionadas as provas comuns, apenas os itens com recursos visuais são adaptados ou substituídos. As adaptaçóes são adequadas e suficientes para eliminar as barreiras e permitir avaliar o que se pretende? Não seria melhor formular itens a partir de matrizes específicas? Nos estudos que o Inep realiza após cada aplicação do exame, seria interessante incluir a verificação da eficácia do processo de adaptação de itens, comparar os desempenhos entre cegos e videntes em cada item que passou e que não passou por adaptação e, enfim, considerar a necessidade de matrizes específicas.

Pessoas com baixa visão podem solicitar a prova ampliada (macrotipo), impressa com fontes tamanhos $18^{14}$ ou 24 e imagens ampliadas. É disponibilizada a opção de auxílio para leitura ou transcrição, com atendimento em sala individual. Os participantes com baixa visão que não solicitam ledor ou transcritor são alocados em salas com até quatro participantes. Porém, as provas ampliadas no Enem não recebem tratamento para garantir maior contraste, e os ledores que atendem aos participantes com baixa visão não contam com um instrumento semelhante à Prova do Ledor, utilizada com os participantes cegos. Em tal caso, o ledor pode se ver obrigado a improvisar descriçôes, criando situações de vulnerabilidade.

Às pessoas com deficiência física, tal como se dá com aquelas com deficiência visual, oferece-se sala de fácil acesso, mesas e cadeiras sem braços, mesas para cadeira de rodas e apoios para perna, além de serviço de ledor/transcritor ${ }^{15}$. 
O Inep faz constar nos contratos com as empresas aplicadoras que haja clara sinalização das rotas de acesso às dependências e disponibilização de pessoal preparado para fornecer informação adequada desde os portóes de ingresso. Também define contratualmente como automática e obrigatória a disponibilização de mobiliário diferenciado a todos os participantes cegos ou com baixa visáo. Reconhece como indispensáveis os recursos necessários para o manuseio adequado da prova em Braille ou a prova ampliada, bem como os materiais que os participantes são autorizados a levar: lupa, telelupa, luminária, máquina Braille, reglete, punção, sorobã, etc. No entanto, há diversos relatos, publicados na imprensa e nas redes sociais, acerca de problemas relativos aos locais de prova: escolas em locais de difícil acesso ou sem acessibilidade predial e mobiliária, iluminação inadequada, insuficiente sinalização de rotas, falta de sanitários para pessoas com deficiência.

Os participantes surdos que realizam a prova com a presença de TILS têm a necessidade de ambiente claro e com bom posicionamento dos intérpretes. Isso precisaria ser previsto, e náo improvisado pela empresa aplicadora no momento do exame. O TILS é disponibilizado para pessoas surdas fluentes em Libras, definido no sistema de inscrição como um "profissional com certificação específica, habilitado para mediar a comunicação entre surdos e ouvintes e, no ato da prova, esclarecer dúvidas dos usuários de Libras na leitura de palavras, expressóes e oraçóes escritas em Língua Portuguesa” (BRASIL, 2012, p. 2). A opção de acessibilidade linguística ao exame propiciada pelo TILS implica uma série de requisitos, a saber: formação prévia do profissional para a atividade; conhecimentos relativos aos temas tratados no exame e características do exame como extensão e condiçóes de aplicação; bem como problemas inerentes à interpretação dos textos em uma atividade complexa como o Enem. Nesse sentido, incorreçóes podem ser geradas, por vezes, pela atividade tradutória, e não por falta de conhecimento ou habilidade do participante. Os critérios de seleção e contratação de TILS para atuarem no exame são frágeis quando se reflete sobre a complexidade do exame e não asseguram uma participação homogênea e isonômica desses nas diferentes salas de exame em todo o país. Não por acaso, há vários anos, a comunidade surda vem reivindicando uma versão do Enem em Libras, de modo que os participantes surdos possam ter acesso à prova em sua primeira língua, direito assegurado aos participantes ouvintes.

Desde 2012, o Inep determina a realização da correção diferenciada das provas escritas (redaçóes) de participantes surdos, deficientes auditivos e disléxicos. No entanto, falta ao Inep apresentar publicamente as matrizes de correção das redações de tais participantes, o que impede um debate mais aprofundado e voltado a contribuir para o seu aprimoramento. Tão fundamental quanto realizar a correção diferenciada é dar transparência aos critérios utilizados, bem como informar e discutir acerca do processo de escolha, contratação e formação das pessoas que compóem as equipes das empresas aplicadoras responsáveis pela correçáo diferenciada das redações. Ao mesmo tempo, é legítimo e necessário refletir sobre a pertinência de se 
realizar, com uma matriz específica, a avaliação do português como segunda língua para o público surdo (FERNANDES, 2012; BATISTA, 2011).

Para os participantes surdocegos, são disponibilizados recursos que contemplam a atuação do guia-intérprete, definido como um "profissional especializado em formas de comunicação e técnicas de guia, tradução e interpretação para mediar a interação entre as pessoas com surdocegueira, a prova e os demais envolvidos na aplicação do Exame". (BRASIL, 2012, p. 3). Ainda, associa-se esse atendimento a prova em grafia Braille ou ampliada, leitura labial e TILS. Tal como ocorre nos casos de outras deficiências, é permitido que os participantes levem os materiais e equipamentos indispensáveis para a sua mobilidade e comunicaçáo. Equipamentos eletrônicos geralmente não são permitidos, salvo casos específicos ${ }^{16}$. Assim, para pessoas que adquiriram surdocegueira pré-linguística, é permitido o uso de objetos de referência, pistas, cadernos de comunicação, desenhos, entre outros. Para pessoas que adquiriram a surdocegueira no período pós-linguístico, pode-se autorizar o uso de materiais técnicos alfabéticos com retransmissão em Braille, língua oral amplificada, etc.

É indispensável garantir formação com cada vez mais qualidade no atendimento diferenciado às equipes que atuam na aplicação. Mais do que apenas receber importantes esclarecimentos em relação à necessidade e à pertinência dos recursos de acessibilidade, as pessoas que coordenam o exame e conduzem as atividades no dia da prova precisam estar cônscias e preparadas em relação às especificidades das pessoas com deficiência, seus direitos e suas necessidades. Isso, obviamente, não desobriga o Inep de aprimorar as provas acessíveis e rediscutir as matrizes do exame à luz das questóes de acessibilidade.

O Inep assegura 60 minutos de tempo adicional em cada dia de exame aos participantes que o requeiram no ato da prova. Trata-se de um benefício assegurado por lei acerca do qual, porém, não há menção nos editais do Enem. Ademais, faltam estudos sobre as condiçôes de sua concessão e de sua eficácia. Todos os que dele precisam fazem a requisição? O tempo adicional é suficiente? Seria preciso adotar pausas para descanso? Em casos extremos, em vez de tempo adicional, seria mais apropriado dispor de novas provas ou outras sistemáticas de aplicaçãa?

A concepção de acessibilidade em um exame não pode ficar restrita a alguns aspectos relativos à aplicação da prova, pois envolve todas as suas etapas. Das Matrizes de Referência à divulgação dos resultados, passando pela produção de itens e provas acessíveis; a elaboração do edital; a criação de sistema de inscrição; a seleção e a formação das equipes de campo, dos profissionais especializados e dos corretores das provas escritas; a definição dos locais de prova, dos recursos a serem disponibilizados e das sistemáticas de aplicação; o monitoramento de cada etapa, tudo deve ser objeto de constante análise, aprimoramento ou reformulação para se garantir a devida acessibilidade. O baixo número de pessoas com deficiência entre os inscritos do Enem indica insuficiências e inadequaçóes nessa área, 
evidenciando, consequentemente, a dramaticidade de um quadro que deve ser enfrentado com rigor e celeridade. Evidentemente, a organização de um exame nacional que envolve milhóes de participantes possui inúmeros desafios. $\mathrm{O}$ da acessibilidade não é o menos importante, sobretudo quando ele se mostra decisivo na vida das pessoas e na garantia de seu direito à educação.

Assim, podem-se perceber avanços em relação ao atendimento diferenciado e à acessibilidade no âmbito das ediçôes do Enem, especialmente se comparado, por exemplo, à oferta de acessibilidade no Exame Nacional de Desempenho do Estudante (Enade), para o qual pouquíssimas adaptaçôes são feitas. Ao mesmo tempo, é possível identificar a necessidade de se promover ajustes e de se adotar medidas voltadas a assegurar um atendimento melhor e mais condizente a esse público.

Por isso, a adoção de medidas eficazes voltadas a garantir o monitoramento criterioso, minucioso e autônomo da aplicaçáo do atendimento diferenciado em todo o país é um dos desafios que o Inep precisa enfrentar (JUNQUEIRA, 2014). Seria importante criar um observatório do Enem, composto por pesquisadores da área, pesquisadores do Inep e lideranças dos movimentos sociais em defesa dos direitos das pessoas com deficiência ${ }^{17}$, de modo a contribuir para identificar falhas e inconsistências, propor aprimoramentos e aprofundar os debates sobre as necessidades e as formas viáveis de ofertar um exame cada vez mais acessível e atento aos direitos do conjunto dos cidadãos.

\section{Notas}

1. Para um histórico do Enem, as reformulações de suas matrizes de referência, a implementação da TRI e as novas finalidades do exame, cf.: INEP (2013).

2. Para a finalidade deste texto, passaremos a nos referir a esse público somente como pessoas com deficiência.

3. Regulamenta as Leis $\mathrm{n}^{\text {os }} 10.048 / 2000$ e $10.098 / 2000$, sendo que a primeira dá prioridade de atendimento às pessoas que específica, e a segunda estabelece normas gerais e critérios para promoção da acessibilidade das pessoas portadoras de deficiência ou com mobilidade reduzida, além de dar outras providências.

4. A partir de 2014, o Inep passou a considerar o Atendimento Diferenciado da seguinte forma: "atendimento especializado", dirigido a participantes com deficiência, síndromes, transtornos globais ou específicos, etc.; e "atendimento específico", dirigido a participantes com mobilidade reduzida, tais como idosos, gestantes e lactantes. Neste artigo, detemo-nos a refletir sobre o primeiro, e não sobre o segundo.

5. Desde 2009, por decisão do MEC, as empresas aplicadoras do Enem são escolhidas em regime de suspensão de licitação. São elas: o Centro de Seleção e de Promoção de Eventos (Cespe) e a Fundaçáo Cesgranrio. Por meio do Decreto n.o 8.078/2013, a Presidência da República 
transformou o Cespe em organizaçáo social (OS) e mudou seu nome para Centro Brasileiro de Pesquisa em Avaliação e Seleção e de Promoção de Eventos (Cebraspe).

6. O Inep divulga em seu portal, em forma de microdados, as informaçóes estatísticas relativas a censos anuais da educação básica e superior, pesquisas, exames e avaliaçôes educacionais sob a sua responsabilidade. Esse material deve ser tratado por softwares específicos, para que, a partir deles, se possa extrair informaçôes a serem apresentadas ao público em geral. Os arquivos podem ser obtidos via download, em formato ASCII, e contêm inputs (canais de entrada) para leitura utilizando os softwares SAS e SPSS. (http://portal.inep.gov.br)

7. Para este estudo, os microdados foram tratados com o software SAS, gerando dados que foram organizados nas tabelas apresentadas. Até o momento, os microdados disponibilizados se referem aos resultados das ediçóes do Enem entre os anos de 1998 e 2014. Os relatórios pedagógicos do Inep divulgados até agora, de acordo com os cronogramas do instituto, referem-se até a edição realizada em 2012. E em função de serem recentes as coletas de informaçóes relativas a participantes com deficiência e ao atendimento diferenciado, o tema passou a integrar os relatórios apenas a partir da edição de 2009.

8. Adota-se, aqui, com a definição de "participante" empregada pelo Inep na produçáo dos microdados do Enem: aquele que realizou todas as provas objetivas e não foi eliminado do exame.

9. É importante observar que, no ato de inscrição ao Enem em 2011 e 2012, foi possível solicitar atendimento diferenciado sem ter informado previamente a deficiência ou a condição que o motivava. Destaca-se tal fato para evitar a conclusão errônea de que teria havido uma redução no número de inscritos e participantes com deficiência no período.

10. É possível inferir determinadas deficiências a partir dos recursos solicitados (tais como prova em Braille, intérprete de Libras, etc.). No entanto, isso não ocorre no caso do participante que não informou a deficiência e solicitou apenas auxílio para leitura ou para transcrição (tais serviços podem ser solicitados pelo público do atendimento diferenciado, exceto surdos e deficientes auditivos). Eles foram 2.276 em 2011 e 1.997 em 2012. Além disso, não se pode excluir a existência de pessoas com deficiência entre os participantes que não informaram uma deficiência e nem solicitaram auxílio ou recurso de acessibilidade.

11. A partir da edição de 2013, não foi mais possível, no ato da inscrição, fazer solicitaçóes de atendimento diferenciado sem informar a deficiência.

12. A partir da edição de 2013, com as mudanças no sistema de inscrição, não foi mais possível informar simultaneamente cegueira e baixa visão, surdez e deficiência auditiva ou, ainda, surdocegueira e qualquer uma das alternativas anteriores. Entre outras providências, foram introduzidos avisos e campos para confirmação das informaçôes fornecidas.

13. Desde 2013, o Inep passou a divulgar uma versáo do edital do Enem em Libras. No entanto, o sistema de inscrição e o questionário socioeconômico, até a edição de 2015, continuam sem janelas em Libras e não há serviço de assistência on-line com TILS.

14. Opção instituída a partir da ediçãoo do Enem de 2013. 
15. Disponível também para pessoas com restriçóes de movimentos de membros superiores.

16. A partir da edição do Enem de 2014, os participantes com discalculia passaram a poder utilizar máquinas calculadoras.

17. Como afirma o lema "Nada sobre nós sem nós", que passou a ser recorrente no Brasil nos debates sobre políticas públicas relacionadas às pessoas com deficiência desde a década de 1990 .

\section{Referências}

BATISTA, M.G.D.A.M. Descrição de singularidades na escrita de surdos. 137 f. Dissertação (Mestrado) - Universidade Federal da Paraíba, João Pessoa, 2011.

BRASIL. Ministério da Educação. Normas técnicas para a produção de textos em Braille. Elaboração: Edison Ribeiro Lemos et al. Brasília: MEC, SEESP, 2006.

Decreto n. ${ }^{\circ} 3.298$, de 20 de dezembro de 1999. Regulamenta a Lei n. ${ }^{\circ} 7.853$, de 24 de outubro de 1989, dispóe sobre a Política Nacional para a Integração da Pessoa Portadora de Deficiência, consolida as normas de proteção, e dá outras providências. Diário Oficial da União, Brasília, 21 dez. 1999.

. Decreto n. ${ }^{0}$ 5.296, de 2 de dezembro de 2004. Estabelece normas gerais e critérios básicos para a promoção da acessibilidade das pessoas portadoras de deficiência ou com mobilidade reduzida e dá outras providências. Diário Oficial da União, Brasília, 3 dez. 2004.

. Decreto n. ${ }^{\circ}$ 5.626, 22 de dezembro de 2005. Regulamenta a Lei n. ${ }^{\circ} 10.436$, de 24 de abril de 2002, que dispóe sobre a Língua Brasileira de Sinais - Libras, e o art. 18 da Lei n. ${ }^{\circ}$ 10.098, de 19 de dezembro de 2000. Diário Oficial da União, Brasília, 23 dez. 2005.

. Lei n. ${ }^{\circ} 7.853$, de 24 de outubro de 1989. Dispóe sobre o apoio às pessoas portadoras de deficiência, sua integraçáo social, sobre a Coordenadoria Nacional para Integração da Pessoa Portadora de Deficiência - Corde, institui a tutela jurisdicional de interesses coletivos ou difusos dessas pessoas, disciplina a atuação do Ministério Público, define crimes, e dá outras providências. Diário Oficial da União, Brasília, 25 out. 1989.

. Lei n. ${ }^{\circ} 10.436$, de 24 de abril de 2002, que dispóe sobre a Língua Brasileira de Sinais - Libras, e o art. 18 da Lei n. ${ }^{\circ}$ 10.098, de 19 de dezembro de 2000. Diário Oficial da União, Brasília, 25 abr. 2002.

. Lei n. ${ }^{\circ}$ 10.098, de 19 de dezembro de 2000. Estabelece normas gerais e critérios básicos para a promoção da acessibilidade das pessoas portadoras de deficiência ou com mobilidade reduzida e dá outras providências. Diário Oficial da União, Brasília, 20 dez. 2000.

- Ministério do Planejamento, Orçamento e Gestão; Ministério da Educação. Modelo de Acessibilidade em Governo Eletrônico. Brasília: MP, SLTI, 2011. Disponível em: https://www.governoeletronico.gov.br/documentos-e-arquivos/e-MAG\%20V3.pdf. Acesso em: janeiro. 2017.

$O$ atendimento diferenciado no ENEM. Brasília: MEC2012. Disponível em: http://download.inep.gov.br/educacao basica/enem/nota tecnica/2012/atendimento diferenciado enem 2012.pdf. Acesso em: 12 dez. 2016. 
. Portaria n.o 807, de 18 de junho de 2010. Institui o Exame Nacional de Ensino Médio. Diário Oficial da União, Brasília, 21 jun. 2010.

FERNANDES, S. Educação de surdos. Curitiba: Intersaberes, 2012.

INSTITUTO NACIONAL DE ESTUDOS E PESQUISAS EDUCACIONAIS ANÍSIO TEIXEIRA (INEP). Exame Nacional do Ensino Médio (Enem): Relatório Pedagógico 20102011. Brasília: Inep, 2013.

Microdados do Enem 2012. Brasília: Inep, 2014. Disponível em <http://portal. inep.gov.br/web/guest/microdados>. Acesso em: 10 fev. 2014.

. Microdados do Enem 2013. Brasília: Inep, 2015. Disponível em: <http://portal. inep.gov.br/web/guest/microdados>. Acesso em: 30 maio 2015.

JUNQUEIRA, R.D. O atendimento diferenciado no Exame Nacional do Ensino Médio. In: MARTINS, L.A.R.; PIRES, G.N.L.; PIRES, J. (Orgs.). Caminhos para uma educação inclusiva. João Pessoa: Universitária da UFPB, 2014.

KULPA, C.C. A contribuição de um modelo de cores na usabilidade das interfaces computacionais para usuários de baixa visão. Dissertação (Mestrado em Design) - Universidade Federal do Rio Grande do Sul, Porto Alegre, 2009.

Recebido em 30 de junho de 2015.

Aprovado em 20 de janeiro de 2017. 